\title{
Pemanfaatan Fasilitas Pelayanan Kesehatan Pemerintah dan Swasta di Kabupaten Sleman
}

\section{Public and Private Health Service Facilities Utilization in Sleman Regency}

\author{
Anita Sulistyorini, Purwanta
}

Bagian Keperawatan Kesehatan Masyarakat Fakultas Kedokteran Universitas Gadjah Mada

\begin{abstract}
Abstrak
Di Sleman, masyarakat yang memanfaatkan fasilitas pelayanan kesehatan swasta (52\%) lebih tinggi daripada yang memanfaatkan fasilitas kesehatan pemerintah (37,6\%). Fenomena ini diduga berhubungan dengan kebijakan kesehatan. Penelitian ini bertujuan mengetahui pola pemanfaatan fasilitas pelayanan kesehatan pemerintah dan swasta oleh keluarga di Kabupaten Sleman serta berbagai faktor yang mempengaruhinya. Penelitian dengan rancangan studi cross sectional ini dilakukan di 13 kecamatan terpilih di Kabupaten Sleman. Teknik pengambilan sampel yang digunakan adalah cluster sampling dua tahap menghasilkan jumlah sampel penelitian 240 responden dari 30 cluster. Instrumen pengumpulan data yang digunakan adalah kuesioner yang sebelumnya telah disiapkan. Metoda uji chi-square digunakan untuk melihat hubungan antara pemanfaatan fasilitas pelayanan kesehatan pemerintah dan swasta dengan status ekonomi, persepsi akses ke fasilitas pelayanan kesehatan, persepsi kualitas pelayanan kesehatan, serta persepsi sehat sakit. Angka pemanfaatan fasilitas pelayanan kesehatan milik pemerintah dan swasta oleh masyarakat di Kabupaten Sleman ternyata sama tinggi yaitu lebih dari $90 \%$. Pemanfaatan fasilitas pelayanan kesehatan pemerintah berhubungan bermakna dengan persepsi aspek waktu pelayanan kualitas pelayanan kesehatan ( $p$ value $=0,019$ ). Fasilitas pelayanan kesehatan swasta berhubungan bermakna dengan persepsi aspek biaya kesehatan kualitas pelayanan kesehatan ( $p$ value $=0,005$ ) Disimpulkan bahwa pemanfaatan fasilitas pelayanan kesehatan milik pemerintah maupun swasta oleh keluarga di Kabupaten Sleman dipengaruhi oleh persepsi kualitas pelayanan kesehatan.
\end{abstract}

Kata kunci: Pemanfaatan, fasilitas pelayanan kesehatan, pemerintah, swasta.

\section{Abstract}

In Sleman, the private health service facilities is utilized higher ( $52 \%$ ) than those of public facilities ( $37,6 \%$ ). This phenomenon is assumed to be brought about by health policy. This research is aimed at studying the pat- tern of private and public health services facilities utilization in Sleman Regency and the factors influence it. A cross-sectional survey was carried out in 13 selected districts of Sleman Regency. Two steps cluster sampling was administered giving 30 clusters and 240 households as respondents. Chi-square test was used to identify association between private and public health services utilization and economical level; the perception of services facilities's accesibility; the perception of health services quality also the perception of family health and healthy illness perception. Both private and public health services facilities in Sleman Regency were equally utilized $(>90) \%$. Utilization of public health services facilities has significant correlation with perception towards health services quality, especially services time ( $p$ valu $e=0,019$ ). The private health services facilities has a significant correlation with the family perception towards health services quality, especially health cost ( $p$ value $=0,005$ ). It is concluded that the family perception towards quality of health services influence the pulic and private health services facilities utilization.

Keywords: Utilization, health services facilities, public, private

\section{Pendahuluan}

Pembangunan kesehatan merupakan upaya pemenuhan salah satu hak dasar rakyat terakses fasilitas pelayanan kesehatan karena kesehatan merupakan hak asasi manusia. Visi dan misi Indonesia Sehat 2010 merupakan bagian dari langkah menuju pencapai tujuan pembangunan kesehatan (nasional) agar bangsa Indonesia mencapai tingkat kesehatan tertentu yang ditandai oleh: 1) hidup dalam lingkungan yang sehat, 2) mempraktikkan perilaku hidup bersih dan sehat, serta

Alamat Korespondensi: Purwanta, Program Studi Ilmu Keperawatan Fakultas Kedokteran Universitas Gadjah Mada, Jl. Farmako Sekip Utara, Yogyakarta, Hp.08122748461, e-mail: purwanta@gmail.com 
3) mampu menyediakan dan memanfaatkan pelayanan kesehatan. ${ }^{1}$ Pembangunan kesehatan menghadapi banyak masalah, antara lain kualitas, pemerataan dan keterjangkauan pelayanan, serta kinerja pelayanan kesehatan yang rendah. ${ }^{2}$ Ketidakpuasan terhadap pelayanan kesehatan lebih menonjol pada pelayanan rawat jalan pemerintah di rumah sakit (RS), puskesmas, dan puskesmas pembantu (pustu) daripada pelayanan swasta di RS, klinik atau balai pengobatan, dan praktik dokter/ bidan/perawat. Kepuasan terhadap pelayanan rawat inap RS pemerintah secara umum lebih rendah daripada pelayanan rawat inap RS swasta. ${ }^{3}$

Hasil Survei Kesehatan Daerah pada tahun 2003 menyatakan bahwa lebih dari 52\% masyarakat di Kabupaten Sleman memanfaatkan pelayanan kesehatan swasta. Angka tersebut jauh lebih besar dibandingkan total pemanfaatan fasilitas kesehatan pemerintah yang hanya mencapai 37,6\%. ${ }^{4}$ Berdasarkan temuan terdapat beberapa faktor yang mempengaruhi masyarakat dalam pemanfaatan fasilitas pelayanan kesehatan milik pemerintah dan swasta. Gejala dominasi pemanfaatan fasilitas pelayanan kesehatan swasta oleh masyarakat menunjukkan ketidakseimbangan proses pencapaian tujuan pembangunan kesehatan. Fenomena ini tentunya menjadi catatan atas kebijakan yang ditetapkan dalam sistem kesehatan. Penelitian ini bertujuan mengetahui pola pemanfaatan keluarga terhadap fasilitas pelayanan kesehatan pemerintah maupun swasta di Kabupaten Sleman serta faktor-faktornya.

\section{Metode}

Jenis penelitian deskriptif analitik ini menggunakan rancangan penelitian cross sectional dengan unit analisis keluarga. Teknik pengambilan sampel yang digunakan adalah cluster sampling dua tahap dengan jumlah sampel penelitian 240 responden yang diambil dari $30 \mathrm{clus}$ ter (dusun) sehingga dari setiap cluster ditarik 8 responden. Instrumen pengumpulan data yang digunakan pada penelitian ini berupa kuesioner yang dibagi menjadi enam bagian meliputi identitas responden, pemanfaatan fasilitas pelayanan kesehatan, status ekonomi keluarga, persepsi akses fasilitas pelayanan kesehatan, persepsi terhadap kualitas pelayanan kesehatan, dan persepsi sehat sakit. Analisis data menggunakan metode analisis data katagorikal dengan uji chi-square dengan nilai $\alpha=$ 0,05 .

\section{Hasil}

\section{Karakteristik Responden}

Sebagian besar responden adalah perempuan (105 orang; 56,3\%), berpendidikan menengah (144; 60\%), bekerja sebagai ibu rumah tangga $(65 ; 27,1 \%)$ dan petani/peternak $(40 ; 16,7 \%)$, berpenghasilan keluarga $\leq$ $\mathrm{Rp}$ 1.000.000,-/bulan yang tergolong rendah (156;
$65,0 \%)$, memanfaatkan fasilitas pelayanan kesehatan pemerintah $(224 ; 93,3 \%)$ dan fasilitas pelayanan kesehatan swasta (229; 95,4\%), dan fasilitas pelayanan kesehatan milik swasta $(130 ; 54,20 \%)$ (Lihat Tabel 1).

Pada Tabel 2 menunjukkan bahwa sebanyak 158 orang $(65,8 \%)$ mempunyai persepsi bahwa fasilitas pelayanan kesehatan milik pemerintah (puskesmas dan RS pemerintah) masih mudah untuk diakses sedangkan sebanyak 150 orang $(62,5 \%)$ berpendapat bahwa fasilitas pelayanan kesehatan milik swasta (bidan/perawat praktik, dokter praktik, balai pengobatan swasta, klinik spesialis, dan RS swasta) masih sulit dijangkau secara jarak dan sarana transportasi.

Persepsi responden terhadap kualitas pelayanan kesehatan milik pemerintah adalah persepsi pada fasilitas kesehatan yang masuk pada kategori memadai, persepsi terhadap petugas kesehatan masuk kategori memuaskan, persepsi terhadap biaya kesehatan masuk kategori murah, dan persepsi terhadap waktu pelayanan kesehatan masuk kategori tidak memuaskan (142 orang atau $59,2 \%)$. Hal ini terlihat berbeda pada persepsi responden terhadap kualitas pelayanan kesehatan milik swasta dimana waktu pelayanan masuk kategori memuaskan (172 orang atau 71,7\%), persepsi terhadap fasilitas kesehatan masuk kategori memadai, persepsi terhadap petugas kesehatan masuk kategori memuaskan, dan persepsi terhadap biaya kesehatan antara kategori mahal dan murah hampir sama, yaitu 121 orang dan 119 orang. Hasil penelitian tentang persepsi sehat sakit responden sebagian besar masuk kategori buruk, yaitu 158 orang $(65,83 \%)$. Adapun responden yang mempunyai persepsi sehat sakit baik hanya sebagian kecil dari total responden yaitu hanya 82 responden $(34,17 \%)$.

\section{Pemanfaatan Fasilitas Pelayanan Kesehatan Pemerintah dan Swasta}

Responden yang memanfaatkan fasilitas pelayanan kesehatan pemerintah $(93,3 \%)$. Hasil analisis bivariat uji chi-square menunjukkan bahwa variabel status ekonomi, persepsi akses ke pelayanan kesehatan, serta persepsi sehat sakit, kepemilikan asuransi tidak berhubungan bermakna dengan pemanfaatan fasilitas pelayanan kesehatan milik pemerintah (nilai $p>0,05$ ). Variabel persepsi kualitas pelayanan kesehatan tentang waktu pelayanan kesehatan dengan pemanfaatan fasilitas pelayanan kesehatan milik pemerintah (nilai $\mathrm{p}=$ 0,019) berhubungan bermakna. Sedangkan, persepsi responden tentang fasilitas, petugas, dan biaya di fasilitas pelayanan kesehatan milik pemerintah tidak mempunyai hubungan yang bermakna dengan pemanfaatan fasilitas pelayanan kesehatan milik pemerintah ( $p$ value $>0,05)$. Berdasarkan hasil tersebut, dapat dikatakan bahwa faktor yang mempengaruhi pemanfaatan fasilitas 
Tabel 1. Karakteristik Responden

\begin{tabular}{llcc}
\hline Karakteristik & Kategori & Frekuensi & Persentase (\%) \\
\hline Jenis kelamin & Laki - laki & 105 & 43,3 \\
Tingkat pendidikan & Perempuan & 135 & 56,7 \\
& Dasar & 54 & 22,5 \\
& Menengah & 144 & 60,0 \\
Pekerjaan & Tinggi & 42 & 17,5 \\
& Ibu rumah tangga & 65 & 27,1 \\
& Petani/peternak & 40 & 16,7 \\
& Wiraswasta & 31 & 12,9 \\
& Buruh & 31 & 12,9 \\
& Karyawan swasta & 22 & 9,2 \\
& PNS/polisi/ABRI & 20 & 8,3 \\
Penghasilan & Pensiunan & 16 & 6,7 \\
Pelayanan kesehatan pemerintah & Lain-lain & 14 & 5,8 \\
\multirow{2}{*}{ Pelayanan kesehatan swasta } & Serabutan & 1 & 0,4 \\
& Rendah & 156 & 65,0 \\
Memanfaatkan fasilitas & Tinggi & 84 & 35,0 \\
kesehatan milik & Memanfaatkan & 224 & 93,3 \\
& Tidak memanfaatkan & 16 & 6,7 \\
& Memanfaatkan & 229 & 95,4 \\
Total & Tidak memanfaatkan & 11 & 4,6 \\
& Pemerintah & 98 & 40,8 \\
& Swasta & 130 & 54,2 \\
\hline & Tidak keduanya & 12 & 5 \\
\hline & & $\mathbf{2 4 0}$ & $\mathbf{1 0 0 , 0}$ \\
\hline
\end{tabular}

Tabel 2. Distribusi Berdasarkan Persepsi Akses, Kualitas, dan Sehat- Sakit

\begin{tabular}{llcc}
\hline Persepsi & Kategori & Frekuensi & Persentase (\%) \\
\hline Akses yankes pemerintah & Mudah & 158 & 65,8 \\
& Sulit & 82 & 34,2 \\
Akses yankes swasta & Mudah & 90 & 37,5 \\
Kualitas yankes pemerintah & Sulit & 150 & 62,5 \\
& Memadai & 178 & 77,39 \\
Kualitas yankes swasta & Tidak memadai & 62 & 22,61 \\
& Memadai & 182 & 79,13 \\
Petugas kesehatan pemerintah & Tidak memadai & 58 & 20,87 \\
\multirow{2}{*}{ Petugas kesehatan swasta } & Memuaskan & 154 & 66,95 \\
& Tidak memuaskan & 86 & 33,05 \\
Waktu pelayanan pemerintah & Memuaskan & 209 & 90,87 \\
\multirow{2}{*}{ Waktu pelayanan swasta } & Tidak memuaskan & 31 & 9,13 \\
\multirow{2}{*}{ Biaya yankes pemerintah } & Memuaskan & 98 & 40,43 \\
\multirow{2}{*}{ Biaya yankes swasta } & Tidak memuaskan & 142 & 59,57 \\
& Memuaskan & 172 & 74,78 \\
Persepsi sehat sakit & Tidak memuaskan & 68 & 25,22 \\
& Murah & 202 & 87,83 \\
& Mahal & 38 & 12,17 \\
& Murah & 121 & 52,60 \\
& Mahal & 119 & 47,40 \\
& Buruk & 158 & 65,83 \\
& Baik & 82 & 34,17
\end{tabular}

pelayanan kesehatan milik pemerintah adalah persepsi terhadap kualitas pelayanan kesehatan yaitu persepsi tentang waktu pelayanan di fasilitas pelayanan kesehatan milik pemerintah (Lihat Tabel 3).

Pemanfaatan fasilitas pelayanan kesehatan milik swasta di Kabupaten Sleman (229; 95,4\%) dengan hasil uji chi-square yang menunjukkan bahwa persepsi akses ke pelayanan kesehatan dan persepsi sehat sakit tidak berhubungan bermakna dengan pemanfaatan fasilitas pelayanan kesehatan swasta ( $p$ value $>0,05)$. Variabel status ekonomi dan kepemilikan asuransi tidak berhubungan bermakna dengan pemanfaatan fasilitas 
Tabel 3. Determinan Pemanfaatan Fasilitas Pelayanan Kesehatan Pemerintah

\begin{tabular}{|c|c|c|c|c|c|c|}
\hline \multirow{3}{*}{ Variabel Independen } & \multirow{3}{*}{ Kategori } & \multicolumn{4}{|c|}{ Pemanfaatan } & \multirow{3}{*}{ Nilai $p$} \\
\hline & & \multicolumn{2}{|c|}{ Ya } & \multicolumn{2}{|c|}{ Tidak } & \\
\hline & & Frek & $\%$ & Frek & $\%$ & \\
\hline \multirow[t]{2}{*}{ Pendapatan } & Rendah & 146 & 60,9 & 10 & 4,17 & 0,828 \\
\hline & TinggI & 78 & 32,5 & 6 & 2,50 & \\
\hline \multirow[t]{2}{*}{ Persepsi akses yankes } & Mudah & 145 & 60,4 & 13 & 5,42 & 0,178 \\
\hline & Sulit & 79 & 32,9 & 3 & 1,25 & \\
\hline \multirow[t]{2}{*}{ Persepsi fasilitas kesehatan } & Memadai & 164 & 68,33 & 14 & 5,83 & 0,207 \\
\hline & Tidak & 60 & 25,0 & 2 & 0,83 & \\
\hline \multirow[t]{2}{*}{ Persepsi petugas kesehatan } & Memuaskan & 143 & 59,6 & 11 & 4,58 & 0,692 \\
\hline & Tidak & 81 & 33,75 & 5 & 2,08 & \\
\hline \multirow[t]{2}{*}{ Persepsi waktu pelayanan } & Memuaskan & 87 & 36,25 & 11 & 4,58 & 0,019 \\
\hline & Tidak & 137 & 57,08 & 5 & 2,08 & \\
\hline \multirow[t]{2}{*}{ Persepsi biaya kesehatan } & Murah & 189 & 78,75 & 13 & 5,42 & 0,741 \\
\hline & Mahal & 35 & 14,58 & 3 & 1,25 & \\
\hline \multirow[t]{2}{*}{ Persepsi sehat sakit } & Buruk & 149 & 62,08 & 9 & 3,75 & 0,403 \\
\hline & Baik & 75 & 31,25 & 7 & 2,92 & \\
\hline \multirow[t]{2}{*}{ Kepemilikan asuransi } & Diharuskan & 63 & 58,9 & 3 & 2,80 & 0,289 \\
\hline & Tidak & 37 & 34,6 & 4 & 3,70 & \\
\hline
\end{tabular}

Tabel 4. Determinan Pemanfaatan Fasilitas Pelayanan Kesehatan Swasta

\begin{tabular}{|c|c|c|c|c|c|c|}
\hline \multirow{3}{*}{ Variabel Independen } & \multirow{3}{*}{ Kategori } & \multicolumn{4}{|c|}{ Pemanfaatan } & \multirow{3}{*}{ Nilai $p$} \\
\hline & & \multicolumn{2}{|c|}{ Ya } & \multicolumn{2}{|c|}{ Tidak } & \\
\hline & & Frek & $\%$ & Frek & $\%$ & \\
\hline \multirow[t]{2}{*}{ Pendapatan } & Rendah & 146 & 60,9 & 10 & 4,17 & 0,065 \\
\hline & Tinggi & 83 & 34,6 & 1 & 0,42 & \\
\hline \multirow[t]{2}{*}{ Persepsi akses } & Mudah & 120 & 50,0 & 4 & 1,70 & 0,298 \\
\hline & Sulit & 109 & 45,4 & 7 & 2,92 & \\
\hline \multirow[t]{2}{*}{ Persepsi fasilitas kesehatan } & Memadai & 173 & 72,08 & 9 & 3,75 & 0,635 \\
\hline & Tidak & 56 & 23,33 & 2 & 0,83 & \\
\hline \multirow[t]{2}{*}{ Persepsi petugas kesehatan } & Memuaskan & 200 & 83,33 & 9 & 3,75 & 0,074 \\
\hline & Tidak & 29 & 12,08 & 2 & 0,83 & \\
\hline \multirow[t]{2}{*}{ Persepsi waktu pelayanan } & Memuaskan & 163 & 67,91 & 9 & 3,75 & 0,444 \\
\hline & Tidak & 66 & 27,5 & 2 & 0,83 & \\
\hline \multirow[t]{2}{*}{ Persepsi biaya kesehatan } & Murah & 120 & 50,0 & 1 & 0,42 & 0,005 \\
\hline & Mahal & 109 & 45,41 & 10 & 4,16 & \\
\hline \multirow[t]{2}{*}{ Persepsi sehat sakit } & Buruk & 151 & 62,92 & 7 & 2,92 & 0,875 \\
\hline & Baik & 78 & 32,5 & 4 & 1,67 & \\
\hline \multirow[t]{2}{*}{ Kepemilikan asuransi } & Diharuskan & 61 & 57,0 & 5 & 4,70 & 0,071 \\
\hline & Tidak & 41 & 38,3 & 0 & 0,00 & \\
\hline
\end{tabular}

pelayanan kesehatan milik swasta (nilai $\mathrm{p}=0,065$ dan 0,071). Persepsi biaya kesehatan di fasilitas pelayanan kesehatan swasta berhubungan bermakna dengan pemanfaatan fasilitas pelayanan kesehatan swasta ( $p$ value $=0,005)$. Dengan demikian, faktor yang mempengaruhi pemanfaatan fasilitas pelayanan kesehatan milik swasta adalah persepsi tentang biaya kesehatan di fasilitas pelayanan kesehatan (Lihat Tabel 4).

\section{Pembahasan}

\section{Status Ekonomi}

Kabupaten Sleman, status ekonomi tidak berhu- bungan bermakna dengan pemanfaatan fasilitas pelayanan kesehatan pemerintah (nilai $\mathrm{p}=0,828$ ). Status ekonomi tidak mempengaruhi keluarga memanfaatkan fasilitas pelayanan kesehatan pemerintah. Hal ini terjadi kemungkinan karena responden dengan tingkat pendapatan tinggi yang bekerja sebagai PNS/polisi/ABRI dan pensiunan tetap memanfaatkan fasilitas pelayanan kesehatan pemerintah. Kepemilikan asuransi mengharuskan mereka memanfaatkan fasilitas pelayanan kesehatan pemerintah. Di samping itu, responden dengan pendapatan tinggi diduga masih mempertimbangkan pelayanan kesehatan yang murah. Tingkat pendapatan tidak 
menunjukkan hubungan yang bermakna dengan pemanfaatan fasilitas pelayanan kesehatan. ${ }^{5}$ Di samping itu, upaya Pemerintah Daerah Kabupaten Sleman meningkatkan kualitas pelayanan kepada masyarakat terbukti dengan tersertifikasi ISO 9001:2000 di RSUD dan 10 puskesmas. Pada tahun 2010 pemerintah daerah menargetkan semua puskesmas di Kabupaten Sleman berstandar internasional. ${ }^{6}$ Hubungan status ekonomi dengan pemanfaatan fasilitas pelayanan kesehatan swasta di Kabupaten Sleman menunjukkan hubungan yang hampir bermakna (nilai $\mathrm{p}=0,065$ ). Tampaknya keluarga memperhitungkan pendapatan dalam memanfaatkan fasilitas pelayanan kesehatan milik swasta.

Responden dengan tingkat pendapatan rendah (156; $65 \%$ ) adalah petani, buruh, pekerja serabutan, dan pekerja lain dengan pendapatan $\leq \mathrm{Rp} 1.000 .000,00$ kemungkinan hanya memenuhi kebutuhan pokok sehari-hari, sehingga fasilitas pelayanan kesehatan swasta dianggap mahal. Perbedaan kelas sosial atau status ekonomi berkaitan dengan prioritas seluruh keluarga. Pada ekonomi tingkat bawah, kesehatan sering diletakkan di daftar kebutuhan paling bawah. ${ }^{7}$ Pada penelitian ini, keluarga dengan tingkat pendapatan tinggi PNS/polisi/ABRI, pensiunan, serta wiraswasta. Tampaknya, semakin baik jenis pekerjaannya dan semakin tinggi pendapatan, maka akan semakin tinggi pula pemanfaatan fasilitas pelayanan kesehatan milik swasta. Kemungkinan kebutuhan pokok kehidupan sehari-hari terpenuhi. Tuntutan kualitas pelayanan kesehatan menjadi prioritas utama dalam menentukan pemanfaatan pelayanan dan masalah biaya dan akses pelayanan tidak dipermasalahkan lagi. Pelanggan umumnya mengharapkan produk berupa barang atau jasa yang dikonsumsi dapat diterima dan dinikmati dengan pelayanan yang baik atau memuaskan. ${ }^{7}$ Keluarga dengan tingkat pendapatan tinggi sebagian besar lebih memilih memanfaatkan fasilitas pelayanan kesehatan swasta. Responden dengan pendapatan tinggi tidak lagi mengutamakan biaya pelayanan kesehatan sehingga memanfaatkan pelayanan kesehatan swasta lebih banyak meski biayanya mahal. ${ }^{8}$

\section{Persepsi Akses ke Fasilitas Pelayanan Kesehatan}

Persepsi akses ke pelayanan kesehatan pemerintah tidak berhubungan bermakna dengan pemanfaatan fasilitas pelayanan kesehatan (nilai $p$ value $=0,178$ ). Bagaimanapun akses pada fasilitas pelayanan kesehatan pemerintah (mudah atau sulit), masyarakat tetap memanfaatkannya. Hal ini berbeda dengan temuan sebelumnya, persepsi akses pelayanan kesehatan juga mempengaruhi pemanfaatan fasilitas pelayanan kesehatan dan lamanya waktu yang digunakan untuk mencapai fasilitas pelayanan kesehatan menurunkan pemanfaatan terhadap fasilitas pelayanan kesehatan. ${ }^{9}$ Kabupaten Sleman mempunyai 14 kecamatan dan 86 desa/kelura- han dan terdapat 4 RS pemerintah, 20 puskesmas perawatan dan 4 non perawatan, 42 pusling, 73 pustu, dan 22 polindes sehingga kondisi tersebut memudahkan masyarakat untuk mengakses pelayanan kesehatan pemerintah. ${ }^{6}$ Persepsi responden tentang akses pelayanan kesehatan tidak berhubungan dengan pemanfaatan fasilitas pelayanan kesehatan swasta di Kabupaten Sleman (nilai $p=0,298$ ). Masyarakat tetap memanfaatkan fasilitas pelayanan kesehatan swasta tidak peduli kesulitan menjangkaunya. Kondisi ini dimungkinkan karena pelayanan kesehatan swasta di Kabupaten Sleman yang banyak meliputi 11 RS swasta, 17 balai pengobatan, 19 rumah bersalin, 11 praktek dokter bersama, 595 praktek dokter, 142 apotik, 5 optik, 12 toko obat, 2 laboratorium klinik, dan 1482 posyandu yang tersebar di semua kecamatan. ${ }^{6,10}$ Hal tersebut akan memudahkan masyarakat mengakses dan didukung kemudahan transportasi. Terbukti dari hasil penelitian ini, 229 orang $(95,4 \%)$ pernah memanfaatkan pelayanan kesehatan swasta. Keadaan tersebut menuntut pelayanan kesehatan memberikan pelayanan yang berkualitas dengan biaya yang terjangkau. Salah satu persyaratan pelanggan bernilai jual tinggi adalah keterjangkauan biaya pelayanan kesehatan. ${ }^{11}$ Lebih dari 52\% masyarakat di Kabupaten Sleman memanfaatkan pelayanan kesehatan swasta. ${ }^{4}$

Aksesibilitas pelayanan kesehatan bukan merupakan faktor yang menentukan dalam pemanfaatan pelayanan kesehatan. ${ }^{12}$ Namun, penelitian lain menyatakan bahwa kemudahan mencapai lokasi unit pelayanan kesehatan merupakan salah satu faktor pendorong untuk menggunakan fasilitas pelayanan kesehatan. ${ }^{13}$ Perbedaan ini disebabkan oleh kondisi geografis Kabupaten Sleman yang memudahkan keluarga menjangkau pelayanan kesehatan dengan kendaraan sendiri atau umum. Sedangkan, di gugus Pulau Seram Barat di Kabupaten Maluku Tengah tidak memungkinkan untuk menjangkau pelayanan kesehatan karena sarana transportasi yang kurang memadai dan berbentuk kepulauan. Selain itu, di Kabupaten Sleman secara fisik fasilitas pelayanan kesehatan milik pemerintah dan swasta dapat dijumpai hampir di setiap wilayah desa atau kecamatan. Dengan demikian, aksesibilitas terutama jarak tidak menjadi penghambat memanfaatkan fasilitas pelayanan kesehatan milik pemerintah dan swasta.

\section{Persepsi Kualitas Pelayanan Kesehatan}

Persepsi responden tentang waktu pelayanan yang berhubungan dengan pemanfaatan fasilitas pelayanan kesehatan milik pemerintah (nilai $\mathrm{p}=0,019$ ) menjelaskan bahwa semakin baik persepsi masyarakat tentang waktu pelayanan di fasilitas pelayanan kesehatan pemerintah, semakin tinggi pemanfaatannya. Apapun kondisi fasilitas, petugas, dan biaya di fasilitas pelayanan kese- 
hatan pemerintah tidak mempengaruhi pemanfaatan oleh masyarakat. Persepsi kualitas pelayanan kesehatan (fasilitas, petugas, maupun biaya) milik pemerintah tidak berhubungan bermakna dengan pemanfaatan fasilitas pelayanan kesehatan pemerintah (nilai $\mathrm{p}>0,05$ ). Pendidikan responden yang sebagian besar rendah dan menengah $(198 ; 82,5 \%)$ dapat membuat responden kurang memperhitungkan masalah kualitas pelayanan kesehatan milik pemerintah terutama tentang fasilitas, petugas, dan biaya kesehatan. Mengingat semakin tinggi pendidikan keluarga, semakin baik pengetahuan keluarga tentang kesehatan. ${ }^{7}$

Persepsi responden tentang biaya kesehatan yang berhubungan dengan pemanfaatan fasilitas pelayanan kesehatan milik swasta (nilai $p=0,005$ ). Biaya kesehatan di fasilitas pelayanan kesehatan swasta yang mahal menjadi pertimbangan tersendiri bagi keluarga untuk memanfaatkan fasilitas pelayanan kesehatan tersebut. Fasilitas, waktu pelayanan, serta petugas kesehatan di fasilitas pelayanan kesehatan tidak berhubungan dengan pemanfaatan fasilitas pelayanan kesehatan milik swasta (nilai $\mathrm{p}>0,05$ ). Hal tersebut berbeda dengan penelitian sebelumnya bahwa alasan responden memanfaatkan pelayanan kesehatan milik swasta bukan hanya dari aspek medis tetapi juga aspek non medis yang lebih baik seperti petugas kesehatan, fasilitas kesehatan dan kondisi umum lainnya sebagai kualitas pelayanan kesehatan. ${ }^{14}$

\section{Persepsi Sehat Sakit}

Persepsi responden tentang sehat sakit tidak memperlihatkan hubungan bermakna dengan pemanfaatan fasilitas pelayanan kesehatan pemerintah (nilai $\mathrm{p}=$ 0,763 ) dan swasta (niai $p=0,875$ ). Apapun persepsi keluarga tentang sehat sakit, tidak mempengaruhi pemanfaatan fasilitas pelayanan kesehatan pemerintah dan swasta. Fasilitas pelayanan kesehatan milik pemerintah dan swasta tetap menjadi pilihan responden dalam kondisi kesehatan apapun. Temuan ini bertentangan dengan penelitian terdahulu bahwa pemanfaatan pelayanan kesehatan dipengaruhi oleh persepsi yang baik terhadap kesehatan. ${ }^{15}$ Perbedaan tersebut mungkin karena tingkat pendidikan responden yang berbeda. Pada penelitian ini, sebagian besar responden berpendidikan tingkat rendah dan menengah $(82,5 \%)$ dan responden yang bekerja sebagai petani, buruh, wiraswasta, dan ibu rumah tangga $(69,6 \%)$ sehingga berpengaruh terhadap interpretasi kondisi kesehatan.

\section{Kesimpulan}

Berdasarkan hasil penelitian, diketahui bahwa tidak ada hubungan antara status ekonomi, persepsi akses ke pelayanan kesehatan, serta persepsi sehat sakit, kepemilikan asuransi dengan pemanfaatan fasilitas pelayanan kesehatan milik pemerintah. Persepsi kualitas pelayanan kesehatan tentang waktu pelayanan kesehatan berhubungan dengan pemanfaatan fasilitas pelayanan kesehatan milik pemerintah. Persepsi kualitas pelayanan kesehatan tentang fasilitas, petugas, dan biaya di fasilitas pelayanan kesehatan milik pemerintah tidak ada hubungan dengan pemanfaatan fasilitas pelayanan kesehatan milik pemerintah. Keluarga memanfaatkan fasilitas pelayanan kesehatan milik pemerintah dan swasta hampir sama tinggi di Kabupaten Sleman. Akses pelayanan kesehatan, persepsi sehat sakit, status ekonomi, dan kepemilikan asuransi tidak ada hubungannya dengan pemanfaatan fasilitas pelayanan kesehatan milik swasta di Kabupaten Sleman. Selain itu, ada hubungan antara biaya kesehatan dengan pemanfaatan fasilitas pelayanan kesehatan milik swasta di Kabupaten Sleman.

\section{Saran}

Saran yang diberikan bagi penyelenggara fasilitas pelayanan kesehatan milik pemerintah (puskesmas dan rumah sakit) untuk lebih meningkatkan kualitas waktu pelayanan kesehatan (memperpendek waktu tunggu) yang diberikan pada masyarakat. Bagi penyelenggara fasilitas pelayanan kesehatan milik swasta agar memberikan akses bagi masyarakat yang mempunyai pendapatan rendah. Bagi Dinas Kesehatan Kabupaten Sleman agar meningkatkan promosi kesehatan melalui pihakpihak penyelenggara fasilitas pelayanan kesehatan setempat untuk meningkatkan persepsi masyarakat tentang pemahaman sehat sakit. Selain itu, bagi peneliti berikutnya akan lebih baik membandingkan fasilitas pelayanan kesehatan milik pemerintah dan swasta yang spesifik seperti rumah sakit saja atau membandingkan pelayanan kesehatan pada puskesmas yang sudah dan belum ISO.

\section{Ucapan Terima Kasih}

Peneliti mengucapkan terimakasih kepada $d r$. Nugrohowiyadi MPH (almarhum) yang telah membimbing penelitian ini sampai proposal. Kepada Pemerintah Kabupaten Sleman di Propinsi DIY atas pemberian izin penelitian ini dan masyarakat yang menjadi responden sehingga penelitian ini terselesaikan dengan baik.

\section{Daftar Pustaka}

1. Departemen Kesehatan Republik Indonesia. Indikator Indonesia sehat 2010 dan pedoman penetapan indikator provinsi sehat dan kabupaten/kota sehat, Keputusan Menteri Kesehatan No.1202/Menkes/ VIII/2003. Jakarta: Departemen Kesehatan Republik Indonesia; 2003.

2. Bappenas. Peningkatan akses masyarakat terhadap layanan kesehatan yang lebih berkualitas. Jakarta: Rencana Kerja Kementerian Lembaga; 2007 [edisi 2007, diakses tanggal 15 November 2007]. Diunduh dari: 
www.bappenas.go.id.

3. Badan Litbang Kesehatan. Laporan data susenas 2001: status kesehatan, pelayanan kesehatan, perilaku hidup sehat dan kesehatan lingkungan. Jakarta: Departemen Kesehatan dan Kesejahteraan Sosial; 2001 [edisi 2001, diakses tanggal 16 September 2007]. Diunduh dari: www.depkes.go.id.

4. Dinas Kesehatan Kabupaten Sleman. Survei status kesehatan daerah Kabupaten Sleman. Yogyakarta: Dinas Kesehatan Kabupaten Sleman; 2003.

5. Hendartini. Determinan pemanfaatan poliklinik gigi FKG-UGM; dari perspektif pasien. Jurnal Manajemen Pelayanan Kesehatan. 2000; 03: 151-9.

6. Dinas Kesehatan Sleman. Profil kesehatan Kabupaten Sleman Yogyakarta. Yogyakarta: Dinas Kesehatan Sleman; 2008.

7. Assouri S. Customer service yang baik landasan pencapaian customer satisfaction. Usahawan. 2003; 01: XXXII: 25-30.

8. Friedman. Keperawatan keluarga: teori dan praktik. Edisi 3. Debora \& Asy (alih bahasa). Jakarta : EGC; 1998.

9. Handayani L, Siswanto, Ma'ruf NA, Hapsari D. Pola pencarian pengo- batan di Indonesia. Analisis Data Susenas 2001. Buletin Penelitian Kesehatan. 2003; 31 (1): 33-47.

10. Dinas Kesehatan Kabupaten Sleman. Sekilas info dinas kesehatan Kabupaten Sleman. Yogyakarta: Dinas Kesehatan Kabupaten Sleman; 2007.

11. Kristiani YR, Kuntjoro T, Utarini A. Pengembangan desain mutu pelayanan rawat inap Puskesmas Karanganyar Kebumen menggunakan quality function development. JMPK. 2006; 09: 209-14.

12. Feldman, Lobo. Global budgets and excass demands for hospital care. Health Economics. 1997; 6: 187-96.

13. Sutikno B. Efektifitas pelayanan kesehatan dengan pendekatan gugus pulau di Gugus Seram Barat [tesis]. Yogyakarta: Universitas Gadjah Mada; 1999.

14. Muntahaza S. Pemanfaatan fasilitas layanan kesehatan oleh keluarga dengan tingkat ekonomi menengah ke atas di Sleman [tesis]. Yogyakarta: Universitas Gadjah Mada; 2004.

15. Laela DS. Determinan permintaan masyarakat terhadap pelayanan kesehatan gigi pada klinik AKG Depkes Bandung [tesis]. Yogyakarta: Universitas Gadjah Mada; 1997. 